PROC. INTERNAT. CONF. SCI. ENGIN.

\title{
KEYNOTE SPEECH
}

\section{Overview of The Forest Fire Research}

\author{
Professor Khaled Chetehouna \\ INSA Centre Val de Loire, Univ. Orléans, PRISME EA 4229, F-18020, Bourges, France
}

\begin{abstract}
Tropical forests play a major role in determining the current atmospheric concentration of greenhouse gases. The role of tropical forests is critical because they are carbon-dense with large amount of carbon is stored. With almost 8 million $\mathrm{km}^{2}$ of the humid tropics, the tropical forests are faced to several issues altering their contribution to the carbon cycle, such as deforestation and wildfires. In Europe, extreme wildfires ravaged the European forests in the last years. These situations were extremely dangerous not only for the environment, but also for the socioeconomical point of view because to the proximity of forests from the urban cities or from the agriculture fields. This fact has motivated the European scientific community to explore the wildfires behavior in the purpose to master their expansion, and limit their harmful effect. In this plenary presentation, the French scientific expertise will be exposed with an eye on a possible extrapolation to the tropical forest's particularity. For this purpose, the following points are going to be discussed: (1) understanding wildfire mechanisms, (2) giving a vision about French scientific experience on forest fires research field, and finally (3) trying to extrapolate these scientific experiences to tropical forests.
\end{abstract}

